\title{
Estudo morfológico e morfométrico da próstata de cobaios (Cavia porcellus, Linnaeus, 1758) durante o desenvolvimento pós-natal
}

\author{
Adriana Gradela $1 *$ \\ Amanda Karoline Rodrigues Nunes ${ }^{1}$ \\ Laura Flávia Teixeira Martins ${ }^{1}$ \\ Juliana Muniz Santos ${ }^{1}$ \\ Maria Helena Tavares de Matos ${ }^{1}$ \\ Bruna Bortoloni Gouveia ${ }^{1}$ \\ Gutemberg Nunes da Silva ${ }^{1}$ \\ Vanessa Sobue Franzo ${ }^{2}$ \\ ${ }^{1}$ Universidade Federal do Vale do São Francisco \\ Rod. 407 km 12 Lote 543, Projeto Nilo Coelho C1, 56300-000 - Petrolina - PE \\ ${ }^{2}$ Universidade Federal do Mato Grosso, Cuiabá - MT, Brasil \\ * Autor para correspondência \\ agradela@hotmail.com
}

Submetido em 29/03/2013

Aceito para publicação em 30/07/2013

\section{Resumo}

A próstata é muito importante clinicamente, pois desempenha um papel importante na produção de sêmen e fertilização do óvulo, além de ser frequentemente acometida por doenças como a hiperplasia prostática e o câncer de próstata. O objetivo deste estudo foi avaliar a morfologia, morfometria, índice organossomático (IOS), espessura da parede e altura do epitélio da próstata de cobaios em diferentes fases do desenvolvimento pós-natal. A partir dos resultados, concluiu-se que a próstata de cobaios assemelha-se a de Chinchilla laniger quanto às unidades túbulo-alveolares; a da paca; cutia e capivara quanto à presença de pregas altas ramificadas na mucosa e a de humanos quanto ao epitélio secretor do tipo cúbico simples. As principais alterações observadas durante o desenvolvimento pós-natal foram o aumento significativo do estroma muscular e da altura do epitélio secretor a partir da pré-puberdade tardia até a pós-puberdade 1 e depois diminuição na pós-puberdade 2 , significativa apenas para o estroma muscular. Estes resultados fundamentam estudos futuros sobre o desenvolvimento pósnatal e de envelhecimento prostático e fundamentam o uso de cobaios como modelo experimental para pesquisas a respeito do complexo prostático.

Palavras-chave: Cavia porcellus; Índice organossomático; Estroma muscular; Epitélio secretor

\section{Abstract}

Morphological and morphometric study of the prostate of guinea pigs (Cavia porcellus, Linnaeus, 1758) during postnatal development. The prostate is clinically very important because it plays an important role 
in the production of sperm and fertilization of the egg, and is frequently affected by diseases, such as prostatic hyperplasia and prostate cancer. The aim of this study was to evaluate the morphology, morphometry, organosomatic index (SOI), wall thickness and height of the prostate epithelium of guinea pigs at different stages of postnatal development. Based on the results, it was concluded that the prostate of guinea pigs resembles the prostate of Chinchilla laniger (because of similar tubulo-alveolar units), pacas and capybara (because of the presence of highly branched mucosal folds) and humans (because of the secretory epithelium of the simple cubic type). The major changes observed during postnatal development were the significant increases in muscle stroma and the height of the secretory epithelium from late prepubertal until post-pubertal 1 , and then a decrease in the post-pubertal 2, which was significant only for the muscle stroma. These results support the need for further studies on the postnatal development and aging of the prostate and substantiate the use of guinea pigs as an experimental model for research on this complex organ.

Key words: Cavia porcellus; Muscle Stroma; Organo-somatic index; Secretory epithelium

\section{Introdução}

A despeito de seu pequeno tamanho, a próstata é muito importante clinicamente, pois desempenha um papel importante na produção de sêmen (CEPEDA et al., 2006) e fertilização do óvulo (CARVALHO, 2005). Suas morfologia e fisiologia têm sido objetos de estudos, pois é frequentemente acometida por doenças como a hiperplasia prostática benigna (HPB), uma das doenças mais comuns nos homens a partir dos 40 anos de idade (AVERBECK et al., 2010) e em cães adultos (MOURA et al., 2006), e o câncer de próstata (CP), que acomete $18 \%$ dos homens e é o tipo mais fatal e frequente de câncer (SROUGI et al., 2008; JEMAL et al., 2010). Isto ocorre porque durante o processo de envelhecimento a glândula prostática sofre alterações histológicas em resposta à variação hormonal, de modo que os andrógenos desempenham um importante papel na HPB e na carcinogênese prostática (MOURA et al., 2006) e o desequilíbrio em seus níveis prostáticos altera a interação entre epitélio e estroma, podendo resultar em descontrole na proliferação, migração e morte celular (JANULIS; LEE, 1999).

Inúmeros estudos têm tentado estabelecer uma correlação funcional e embriológica entre as regiões da próstata humana e os lobos prostáticos de roedores, sem evidências conclusivas até o momento (MARKER et al., 2003; SHAPPELL et al., 2004). Por isso, cobaios podem ser uma alternativa viável, pois apresentam rápido desenvolvimento reprodutivo (GRADELA et al., 2012); longo período de gestação, ovulação espontânea e corpo lúteo ativo (SUZUKI et al., 2003) e similaridade do epitélio e estroma de sua próstata com a de humanos. Entretanto, a literatura disponibiliza apenas estudos morfológicos em animais adultos (NEUHAUS et al., 2001; VÁSQUEZ; DEL SOL, 2010), havendo carência de estudos correlacionando o desenvolvimento morfométrico e morfológico da próstata, à idade e ao desenvolvimento corporal e atividade reprodutiva. Este fato pode dificultar os estudos, pois embora o controle do crescimento prostático em cobaios não sofra influência do fotoperíodo, ele parece ser influenciado pela idade, visto que durante o envelhecimento há um aumento da massa do estroma, fibrose estromal significativa e prostatite ocasional, similarmente ao que se observa em homens de idade avançada (VÁSQUEZ; DEL SOL, 2010).

A próstata é constituída de um epitélio secretor e um estroma, cujo status funcional e organização são controlados por andrógenos. Pelo papel desempenhado na manutenção da homeostase da próstata e do seu envolvimento morfofisiológico em doenças tais como a hiperplasia benigna da próstata e câncer, o estroma prostático tem sido considerado como o compartimento principal de funcionamento glandular (ZHANG et al., 2003), pois influencia diretamente o comportamento epitelial (THOMSON, 2001). Entretanto, o estroma também é regulado pelo epitélio, de modo que o desenvolvimento da próstata, assim como a manutenção de seu estágio funcional adulto, depende das interações parácrinas entre o estroma e o epitélio (HAYWARD; CUNHA, 2000). Entretanto os detalhes moleculares deste fato permanecem desconhecidos (THOMSON, 2001).

Diante do exposto, objetivou-se avaliar alguns aspectos morfológicos, morfométricos e estruturais 
da próstata de cobaios em diferentes fases do desenvolvimento pós-natal, visando contribuir com dados científicos para seu uso como modelo experimental em doenças prostáticas.

\section{Material e Métodos}

Esta pesquisa foi aprovada pelo Comitê de Ética em Estudos Humanos e Animais da Universidade Federal do Vale do São Francisco, UNIVASF (Protocolo $\mathrm{n}^{\circ}$ 22041017). Cobaios (Cavia porcellus) criados no biotério da Universidade Federal do Vale do São Francisco em Petrolina, Estado de Pernambuco, Brasil (Latitude: 09²3' 55"/Longitude: 40³0'03"/Altitude: $376 \mathrm{~m}$ ), foram divididos, ao acaso, em cinco grupos de cinco animais cada $(\mathrm{N}=25)$, cada grupo correspondendo a uma idade e fase do desenvolvimento pós-natal (GRADELA et al., 2012): grupo 1 - fase impúbere (primeira semana após o nascimento); grupo 2 - fase pré-púbere inicial (terceira semana após o nascimento); grupo 3 - fase pré-púbere tardia (quinta semana após o nascimento); grupo 4 - fase pós-púbere 1 (nona semana após o nascimento) e grupo 5 - fase pós-púbere 2 (décimaprimeira semana após o nascimento).

\section{Registrosmorfométricosmacroscópicos}

Os espécimes foram desmanados na quarta semana após o nascimento, quando receberam água e ração comercial ad libitum, até o momento da avaliação. Após avaliação da massa corporal (MC) em balança comum, os animais foram submetidos à anestesia dissociativa com cloridrato de xilazina e cloridrato de ketamina na diluição $1: 5(0,1 \mathrm{~mL} / 100 \mathrm{~g} \mathrm{PV})$ [IM] associados ao cloridrato de tramadol (2 mg/1000 g) [IM] e eutanásia por exanguinação. A próstata foi identificada, dissecada e extirpada da cavidade pélvica para estudo morfométrico, sendo a massa (MP) estimada em balança analítica KERN 430-21 $\max 50 \mathrm{~g} \mathrm{~d}=0,001 \mathrm{~g}$; o volume (VP) considerando-se o deslocamento de solução salina $\mathrm{NaCl}$ a 9\% em uma proveta graduada (MANDARIM-DELACERDA, 1994) e o comprimento (CP), largura (LP) e espessura (EP) com o auxílio de um paquímetro de precisão milimetral. O índice organossomático (IOS) foi determinado, de acordo com a fórmula: $\operatorname{IOS}(\%)=\mathrm{MP} /$ MC (g) x 100, em cada semana de idade.

\section{Histologia e registros morfométricos microscópicos}

Em cada idade, fragmentos da próstata $(\mathrm{N}=3 /$ grupo etário) foram fixados em formalina tamponada a $10 \%$ por $18 \mathrm{~h}$ e imersos em álcool $70 \%$ até o processamento histológico de rotina e coloração por hematoxilinaeosina (HE). As lâminas depois de coradas e montadas foram analisadas em microscópio binocular Olympus BX 50 equipado com câmera digital e as imagens com o software Motic Imagens Plus 2.0. A espessura do estroma muscular da próstata foi medida em 10 cortes da glândula por idade, com aumento de 10X, em quatro pontos correspondentes às alturas máximas da parede, sem incluir a mucosa, obtendo-se, assim, a média por idade. A altura do epitélio secretor foi determinada com um aumento de 40X, medindo-se a altura do epitelio nas mesmas zonas descritas anteriormente, obtendo-se a média por idade.

\section{Análises estatísticas}

Os valores obtidos foram expressos em média \pm desvio padrão (SD). Os dados distribuíram-se de forma paramétrica (teste de normalidade de Kolmogorov Smirnov $\mathrm{p}>0,1)$ e as médias foram comparadas pelo teste de Tukey $(\mathrm{P}<0,05)$. Coeficiente de correlação simples (r) foi analisado entre as variáveis (Assistat 7,6 beta).

\section{Resultados}

A próstata de cobaios é uma glândula ímpar localizada na superfície dorsal da uretra pélvica caudalmente a glândula coaguladora, glândulas vesiculares e ductos deferentes e cranialmente à uretra pélvica e glândulas bulbouretrais. Apresenta forma irregular, bordas folheadas e, em sua superfície dorsal, um sulco superficial (istmo) que a divide em dois lobos, o direito e o esquerdo. Seus condutos excretores desembocam caudalmente aos condutos das glândulas vesiculares e coaguladoras e dos ductos deferentes (Figura 1). 
FIGURA 1: Fotomacrografia da porção caudal do aparelho reprodutor masculino de cobaio (Cavia porcellus). A - fase pré-púbere inicial (terceira semana após o nascimento); B - fase pré-púbere tardia (quinta semana após o nascimento); C - fase pós-púbere 1 (nona semana após o nascimento) e D - fase pós-púbere 2 (décima-primeira semana após o nascimento). (1) testículo; (2) cauda do epidídimo; (3) ducto deferente; (4) glândulas vesiculares, (5) vesícula urinária; (6) próstata; (7) uretra pélvica.
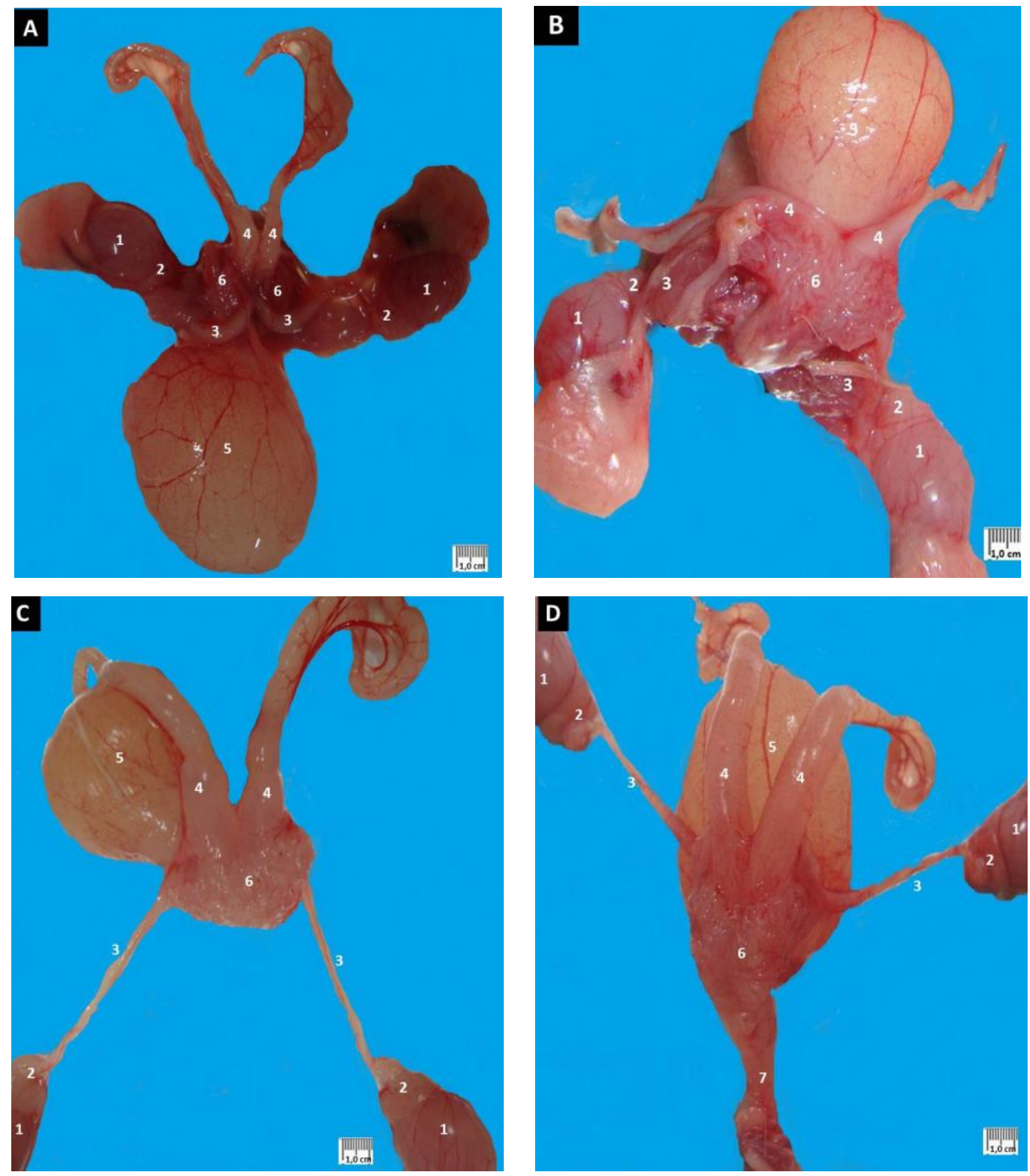
A MC aumentou $(\mathrm{P}<0,05)$ progressivamente durante o desenvolvimento pós-natal, apresentando um aumento máximo de 4,3 vezes na pós-puberdade 2 . A MC variou de 112,56 $\pm 1,52 \mathrm{~g}$ na fase impúbere a 489,05 $\pm 21,18 \mathrm{~g}$ na pós-púbere 2 (Tabela 1 ).

As mensurações da próstata, depois de retirada da cavidade, mostraram que os lobos prostáticos direito e esquerdo não apresentaram diferença estatística, por isso foram apresentados apenas os dados do lobo direito. A MP aumentou 5,7 vezes $(\mathrm{P}<0,05)$ da fase impúbere à pré-púbere inicial, manteve o aumento em torno de 5,5, vezes até a fase pós-púbere 1 e então aumentou 11 vezes $(\mathrm{P}<0,05)$ o seu tamanho na fase pós-púbere 2 , variando de $0,04 \pm 0,02$ g a $0,44 \pm 0,11 \mathrm{~g}$ (Tabela 1$)$.

O valor mais alto do IOS foi observado na fase prépúbere inicial $(0,11 \pm 0,02 \%)$ e, nas fases subsequentes, sofreu ligeira diminuição $(\mathrm{P}>0,05)$ até a pós-puberdade
$2(0,09 \pm 0,02)$, variando de $0,04 \pm 0,02$ a $0,11 \pm 0,02 \%$ (Tabela 1). O coeficiente de correlação calculado entre o IOS e a MC foi não significativo, enquanto que entre o IOS e a MP foi muito significativo $(\mathrm{P}<0,01)$ nas fases impúbere; pré-púbere tardia e pós-púbere 2 (Tabela 2).

O VP, CP, LP e EP apresentaram uma curva de crescimento com tendência linear crescente, havendo aumento significativo no CP na pós-puberdade 1 e no VP e LP na pré-puberdade tardia. O maior aumento na morfometria foi observado no VP (10 vezes), seguido da LP (4,4 vezes), CP (3,1 vezes) e EP (2,8 vezes). $\mathrm{O} \mathrm{VP}$ e o $\mathrm{CP}$ aumentaram progressivamente entre as idades atingindo valores máximos na pós-puberdade 2 , enquanto que a LP atingiu o aumento máximo na fase pós-púbere 1 e depois sofreu ligeira diminuição $(\mathrm{P}>0,05)$ na pós-púbere 2 e a EP manteve-se praticamente inalterada $(\mathrm{P}>0,05)$ (Tabela 3$)$.

TABELA 1: Massa corporal (MC), massa prostática (MP) e índice organossomático (IOS) de cobaios (Cavia porcellus) durante o desenvolvimento pós-natal, Petrolina-2011.

\begin{tabular}{ccccccc}
\hline Fase & MC $(\mathbf{g})$ & $\mathbf{A}(\mathbf{X})$ & $\mathbf{M P}(\mathbf{g})$ & $\mathbf{A}(\mathbf{X})$ & IOS $(\%)$ & $\mathbf{A}(\mathbf{X})$ \\
\hline $\mathrm{Im}$ & $112,56+1,52 \mathrm{e}$ & & $0,04+0,02 \mathrm{c}$ & & $0,04+0,02 \mathrm{c}$ & \\
$\mathrm{Pi}$ & $225,49+18,53 \mathrm{~d}$ & 2,0 & $0,23+0,04 \mathrm{~b}$ & 5,7 & $0,11+0,02 \mathrm{a}$ & 2,7 \\
$\mathrm{Pt}$ & $285,04+17,54 \mathrm{c}$ & 2,5 & $0,23+0,09 \mathrm{~b}$ & 5,7 & $0,08+0,03 \mathrm{abc}$ & 2,0 \\
$\mathrm{Pp} 1$ & $382,85+24,88 \mathrm{~b}$ & 3,4 & $0,21+0,01 \mathrm{~b}$ & 5,2 & $0,05+0,02 \mathrm{bc}$ & 1,2 \\
$\mathrm{Pp} 2$ & $489,05+21,18 \mathrm{a}$ & 4,3 & $0,44+0,11 \mathrm{a}$ & 11,0 & $0,09+0,02 \mathrm{ab}$ & 2,2 \\
\hline
\end{tabular}

ANOVA post hoc (teste de Tukey). A= aumento (vezes). Im - fase impúbere (primeira semana após o nascimento); Pi - pré-púbere inicial (terceira semana após o nascimento); Pt - pré-púbere tardia (quinta semana após o nascimento); Pp1 - pós-púbere 1 (nona semana após o nascimento) e Pp2 - pós-púbere 2 (décima-primeira semana após o nascimento).

TABELA 2: Coeficientes de correlação simples (r) e níveis de significância (P) entre índice organossomático (IOS), massa corporal (MC) e massa da próstata (MP) de cobaios (Cavia porcellus) durante o desenvolvimento pós-natal. Petrolina 2011.

\begin{tabular}{ccccc}
\hline Fase & IOS x MC (r) & $\mathbf{P}$ & IOS x MP (r) & $\mathbf{P}$ \\
\hline $\mathrm{Im}$ & 0,43 & $>0,05$ & 1,00 & $<0,01$ \\
$\mathrm{Pi}$ & 0,47 & $>0,05$ & 0,45 & $>0,05$ \\
$\mathrm{Pt}$ & 0,18 & $>0,05$ & 0,98 & $<0,01$ \\
$\mathrm{Pp} 1$ & 0,53 & $>0,05$ & 0,61 & $>0,05$ \\
$\mathrm{Pp} 2$ & 0,73 & $>0,05$ & 0,99 & $<0,01$ \\
\hline
\end{tabular}

Im - fase impúbere (primeira semana após o nascimento); Pi - pré-púbere inicial (terceira semana após o nascimento); Pt - pré-púbere tardia (quinta semana após o nascimento); Pp1 - pós-púbere 1 (nona semana após o nascimento) e Pp2 - pós-púbere 2 (décima-primeira semana após o nascimento). 
TABELA 3: Morfometria do lobo direito da próstata de cobaios (Cavia porcellus) durante o desenvolvimento pós-natal. PetrolinaPE, 2010.

\begin{tabular}{ccccccccc}
\hline Fase & $\begin{array}{c}\mathbf{V P} \\
(\mathbf{m L})\end{array}$ & $\begin{array}{c}\mathbf{A} \\
(\mathbf{X})\end{array}$ & $\begin{array}{c}\mathbf{C P} \\
(\mathbf{c m})\end{array}$ & $\begin{array}{c}\mathbf{A} \\
(\mathbf{X})\end{array}$ & $\begin{array}{c}\mathbf{L P} \\
(\mathbf{c m})\end{array}$ & $\begin{array}{c}\mathbf{A} \\
(\mathbf{X})\end{array}$ & $\begin{array}{c}\mathbf{E P} \\
(\mathbf{c m})\end{array}$ & $\begin{array}{c}\mathbf{A} \\
(\mathbf{X})\end{array}$ \\
\hline $\mathrm{Im}$ & $0,03 \pm 0,00^{\mathrm{c}}$ & & $0,44 \pm 0,10^{\mathrm{b}}$ & & $0,19 \pm 0,02^{\mathrm{c}}$ & & $0,10 \pm 0,00^{\mathrm{a}}$ & \\
$\mathrm{Pi}$ & $0,15 \pm 0,03^{\mathrm{bc}}$ & 5,0 & $0,92 \pm 0,21^{\mathrm{ab}}$ & 2,1 & $0,42 \pm 0,05^{\mathrm{bc}}$ & 2,2 & $0,26 \pm 0,08^{\mathrm{a}}$ & 2,6 \\
$\mathrm{Pt}$ & $0,24 \pm 0,08^{\mathrm{ab}}$ & 8,0 & $0,90 \pm 0,25^{\mathrm{ab}}$ & 2,0 & $0,54 \pm 0,26^{\mathrm{ab}}$ & 2,8 & $0,28 \pm 0,10^{\mathrm{a}}$ & 2,8 \\
$\mathrm{Pp} 1$ & $0,25 \pm 0,06^{\mathrm{ab}}$ & 8,3 & $1,35 \pm 0,56^{\mathrm{a}}$ & 3,1 & $0,84 \pm 0,14^{\mathrm{a}}$ & 4,4 & $0,26 \pm 0,05^{\mathrm{a}}$ & 2,6 \\
$\mathrm{Pp} 2$ & $0,30 \pm 0,12^{\mathrm{a}}$ & 10,0 & $1,38 \pm 0,34^{\mathrm{a}}$ & 3,1 & $0,70 \pm 0,26^{\mathrm{ab}}$ & 3,7 & $0,22 \pm 0,19^{\mathrm{a}}$ & 2,2 \\
\hline
\end{tabular}

ANOVA post hoc (teste de Tukey). Im - fase impúbere (primeira semana após o nascimento); Pi- pré-púbere inicial (terceira semana após o nascimento); Pt- pré-púbere tardia (quinta semana após o nascimento); Pp1- pós-púbere 1 (nona semana após o nascimento) e Pp2- póspúbere 2 (décima-primeira semana após o nascimento).

A Tabela 4 exibe o coeficiente de correlação simples (r) entre a idade, biometria corporal e morfometria da próstata de cobaios. A idade apresentou correlação significativa com os parâmetros biométricos corporais e com o VP e CP. Os parâmetros biométricos corporais foram correlacionados significativamente entre sí e com o VP e CP e os parâmetros morfométricos da próstata foram correlacionados entre sí, excetuandose a MP e EP.

Histologicamente a próstata é constituída de unidades túbulo-alveolares arredondadas ou poligonais, com pregas complexas, que se abrem numa cavidade central grande, ocupada, em parte, por secreção homogênea acidófila. O epitélio secretor é composto de células simples cúbicas e rodeado por abundante tecido muscular liso e pouco tecido conjuntivo. $\mathrm{O}$ desenvolvimento da glândula foi notado por meio do aumento da espessura do epitélio cúbico simples e do aumento da projeção das pregas da túnica mucosa em direção a luz (Figura 2).

As análises morfológica e morfométrica na próstata de cobaios demostraram um significante aumento no estroma muscular e na altura do epitélio secretor a partir da pré-puberdade tardia que atingiu valores máximos na pós-puberdade 1 . Na pós-puberdade 2 houve diminuição tanto do estroma muscular quanto da altura do epitélio, sendo esta diminuição significativa apenas para o estroma muscular (Tabela 5). Correlação positiva significativa $(\mathrm{P}<0,05)$ foi observada entre EM e a $\mathrm{LP}(\mathrm{r}=$ $0,98)$ e entre $\operatorname{AE~e~LP~}(r=0,98)$.

TABELA 4: Coeficientes de correlação simples (r) entre a idade, biometria corporal e morfometria da próstata de cobaios (Cavia porcellus). Petrolina-2011.

\begin{tabular}{ccccccccc}
\hline & MC & CC & AC & MP & VP & CP & LP & EP \\
\hline Fase & $0,92^{*}$ & $0,97^{* *}$ & $0,96^{*}$ & $0,87^{\mathrm{NS}}$ & $0,99^{* *}$ & $0,93^{*}$ & $0,88^{\mathrm{NS}}$ & $0,23^{\mathrm{NS}}$ \\
MC & - & $0,99^{* *}$ & $0,98^{* *}$ & $0,90^{*}$ & $0,98^{* *}$ & $0,95^{*}$ & $0,89^{*}$ & $0,32^{\mathrm{NS}}$ \\
$\mathbf{C C}$ & - & - & $0,98^{* *}$ & $0,90^{*}$ & $0,95^{*}$ & $0,98^{* *}$ & $0,92^{*}$ & $0,40^{\mathrm{NS}}$ \\
AC & - & - & - & $0,92^{*}$ & $0,94^{*}$ & $0,93^{*}$ & $0,88^{\mathrm{NS}}$ & $0,49^{\mathrm{NS}}$ \\
MP & - & - & - & - & $0,80^{\mathrm{NS}}$ & $0,82^{\mathrm{NS}}$ & $0,67^{\mathrm{NS}}$ & $0,55^{\mathrm{NS}}$ \\
VP & - & - & - & - & - & $0,92^{*}$ & $0,90^{*}$ & $0,43^{\mathrm{NS}}$ \\
CP & - & - & - & - & - & - & $0,96^{*}$ & $0,32^{\mathrm{NS}}$ \\
LP & - & - & - & - & - & - & - & $0,25^{\mathrm{NS}}$ \\
\hline
\end{tabular}

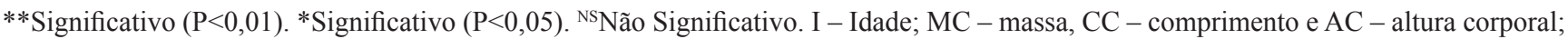
$\mathrm{MP}$ - massa, VP - volume, CP - comprimento, LP - largura e EP - espessura da próstata. 
FIGURA 2: Fotomicrografia da próstata de cobaios na pré-puberdade inicial (A); pré-puberdade tardia (B); pós-puberdade 1 (C) e póspuberdade 2 (D). Nota-se o desenvolvimento da glândula diante do aumento da espessura do epitélio cúbico simples (*) e da projeção das pregas da túnica mucosa (MU) em direção a luz. ME - túnica média constituída de tecido muscular liso (triângulo) com pouco tecido conjuntivo. HE, $10 \mu \mathrm{m}$.

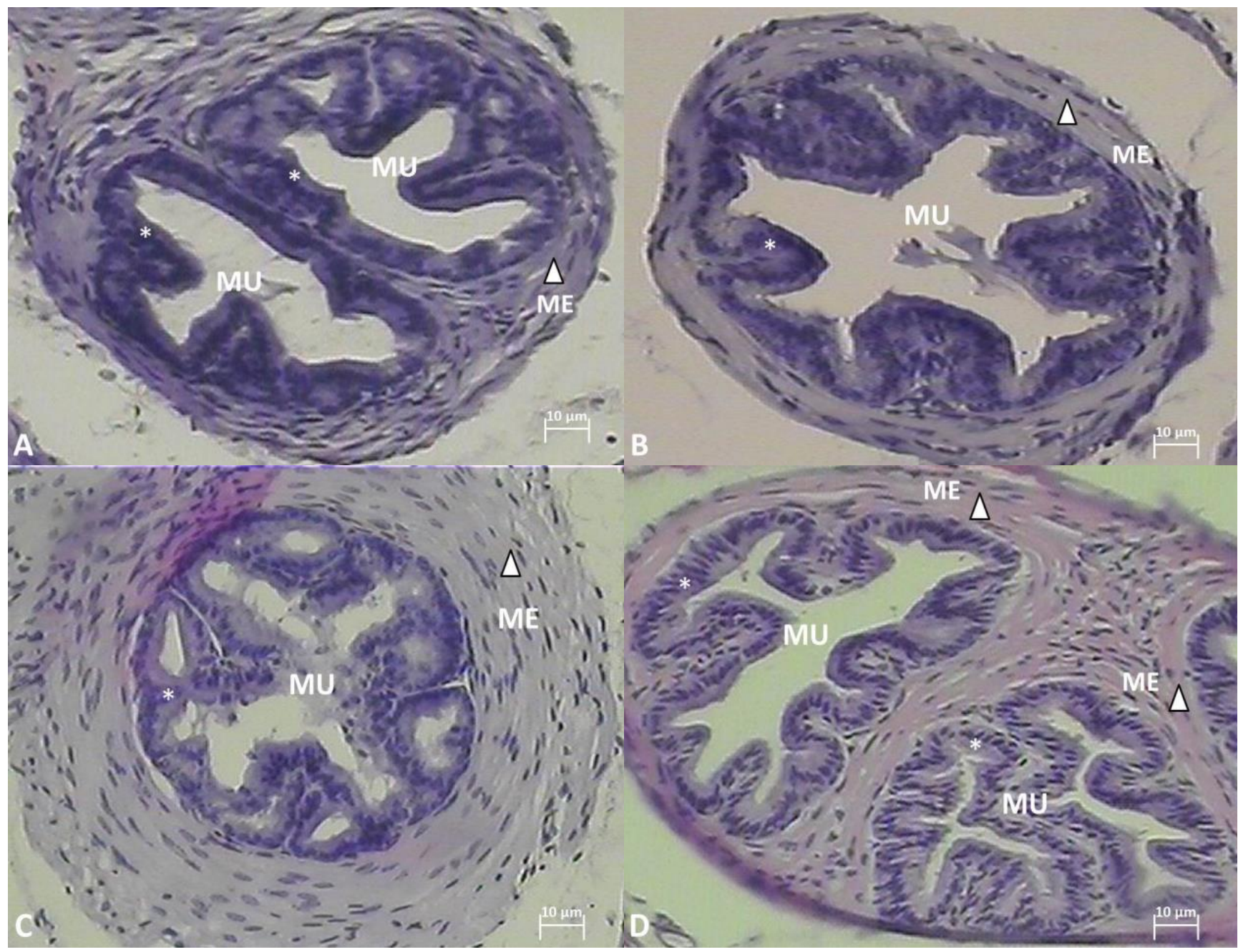

TABELA 5: Estroma muscular e altura do epitélio secretor da próstata durante o desenvolvimento pós-natal de cobaios (Cavia porcellus). Petrolina, 2011.

\begin{tabular}{ccccc}
\hline Fase & Estroma muscular $(\boldsymbol{\mu m})$ & $\begin{array}{c}\text { Aumento } \\
(\mathbf{x})\end{array}$ & Altura do epitélio $(\boldsymbol{\mu m})$ & $\begin{array}{c}\text { Aumento } \\
(\mathbf{x})\end{array}$ \\
\hline $\mathrm{Im}$ & $25,67 \pm 3,50^{\mathrm{c}}$ & & $17,28 \pm 1,34^{\mathrm{c}}$ & \\
$\mathrm{Pi}$ & $31,70 \pm 4,96^{\mathrm{c}}$ & 1,2 & $20,91 \pm 2,20^{\mathrm{c}}$ & 1,2 \\
$\mathrm{Pt}$ & $57,85 \pm 9,49^{\mathrm{b}}$ & 2,2 & $32,37 \pm 4,11^{\mathrm{b}}$ & 1,9 \\
$\mathrm{Pp} 1$ & $100,73 \pm 22,41^{\mathrm{a}}$ & 3,9 & $60,31 \pm 10,53^{\mathrm{a}}$ & 3,5 \\
$\mathrm{Pp} 2$ & $68,71 \pm 9,89^{\mathrm{b}}$ & 2,7 & $54,39 \pm 14,86^{\mathrm{a}}$ & 3,1 \\
\hline
\end{tabular}

ANOVA post hoc (Teste de Tukey). Im - fase impúbere (primeira semana após o nascimento); Pi- pré-púbere inicial (terceira semana após o nascimento); Pt- pré-púbere tardia (quinta semana após o nascimento); Pp1- pós-púbere 1 (nona semana após o nascimento) e Pp2- póspúbere 2 (décima-primeira semana após o nascimento). 


\section{Discussão}

A próstata é uma glândula sexual acessória hormônio-dependente, cujo estudo de sua morfologia e fisiologia é essencial devido a sua importância clínica na reprodução masculina e às condições patológicas que a atingem, como a hiperplasia prostática benigna e o câncer prostático (MARCELLI; CUNNINGHAM, 1999).

Embora presente em todas as classes de mamíferos, a morfologia prostática varia de modo significativo quanto ao número, localização e características entre os roedores e até dentro de uma mesma espécie. Nos cobaios deste estudo, encontrava-se constituída de dois lobos unidos por um sulco superficial (istmo) concordando com Vasquez e Del Sol (2010), mas confrontou-se com as descrições de Cooper e Schiller (1975) e Orti et al. (2004) nesta mesma espécie, que observaram, respectivamente, um lobo pequeno caudal e um lobo maior cranial e dois pares de lóbulos, um pequeno ventral à uretra e outro grande e dorsal, unidos por um istmo transverso. Comparando-se com outros roedores, a glândula prostática de cobaios contrasta com os dois pares de lobos, os ventrais dispostos lateralmente à uretra e os dorsais um de cada lado da uretra, da cutia (MENEZES, 2001); os lobos dorsal e ventral da paca (BORGES, 2004); a divisão em vários lobos unidos da capivara (FERNANDEZ, 2003) e os três pares de lobos, ventral, lateral e dorsal do rato (CARVALHO, 2005). Além disso, a organização multilobar da próstata não é observada em humanos adultos, nos quais ela apresenta-se como um órgão compacto com regiões distintas intimamente associadas (TABOGA et al., 2009). A localização pélvica em contato direto com a glândula vesicular concordou com a de outros roedores (MENEZES, 2001; FERNANDEZ, 2003; BORGES, 2004; VÁSQUEZ; DEL SOL, 2010), enquanto que o aspecto folheado assemelhou-se ao da paca (BORGES, 2004) e diferiu do formato bastante variável da capivara (FERNANDEZ, 2003).

A massa corporal dos cobaios variou significativamente entre as idades, aumentando progressivamente, enquanto que a massa prostática permaneceu estável da fase pré-púbere inicial até a fase pós-púbere 1 e voltou a aumentar na fase póspúbere 2. Consequentemente, foi observada correlação positiva significativa apenas entre a idade e a massa corporal, enquanto que a correlação entre a idade e a massa prostática foi não significativa. Estes achados concordaram parcialmente com o descrito em ratos Wistar, nos quais ambas as correlações são significativas (MUKERJEE; RAJAN, 2004).

Analisando-se o aumento na massa corporal e prostática dos cobaios percebe-se que a massa prostática apresentou aumento muito superior ao da massa corporal em todas as fases do desenvolvimento pós-natal, particularmente na pós-púbere 2 (11,0 vs 4,3 vezes, respectivamente, Tabela 1). A carência de estudos descrevendo o desenvolvimento corporal e prostático pós-natal de cobaios impediu uma comparação ampla de nossos resultados, pois os únicos estudos a abordarem cobaios em diferentes fases do desenvolvimento pós-natal descrevem apenas alterações histológicas (HORSFALL et al., 1994; CORDEIRO et al., 2004).

Neste estudo não foi observada correlação significativa entre massa corporal e IOS, fato que sugeriu que eles não são bons indicadores de variações nos órgãos reprodutivos em concordância com os achados de Cepeda et al. (2006). Por outro lado, a elevada $(\mathrm{P}<0,01)$ correlação entre o IOS e a massa da próstata nas fases impúbere, pré-púbere tardia e pós-púbere 2 indicou que este índice refletiu melhor a atividade reprodutiva que a massa corporal. Isto é explicado pela influência dos andrógenos no desenvolvimento da próstata, pois nos períodos de concentrações séricas relativamente baixas de andrógenos (fases impúbere e pré-púbere tardia), ocorre o crescimento e a diferenciação da glândula e nos de concentrações séricas altas a máxima atividade secretora e a manutenção da glândula (fase pós-púbere 2). A correlação positiva significativa entre a idade e o volume $(\mathrm{r}=0,99, \mathrm{P}<0,01)$ e idade e comprimento prostático $(\mathrm{r}=0,93, \mathrm{P}<0,05)$ confirmaram estes achados.

Histologicamente, a próstata de cobaios apresentou epitélio colunar simples, assim como o considerado para humanos (JUNQUEIRA; CARNEIRO, 2005), contrastando com o epitélio pseudo-estratificado cilíndrico com algumas áreas de epitélio simples cilíndrico da capivara (FERNANDEZ, 2003), colunar 
simples com tendência a pseudo-estratificado da paca (BORGES, 2004) e colunar pseudo-estratificado da cutia (MENEZES, 2001). A estrutura túbulo-alveolar envolta por cápsula fibroelástica, rica em músculo liso, foi igualmente referida em Chinchilla laniger (CEPEDA et al., 2006), enquanto que a presença de pregas altas ramificadas na mucosa concordou com a paca (BORGES, 2004); cutia (MOLLINEAU et al., 2009) e capivara (FERNANDEZ et al., 2010).

$\mathrm{Na}$ pré-puberdade iniciaram-se os aumentos significativos no estroma muscular e na altura do epitélio, que aumentaram progressivamente até a pós-puberdade 1. Estes achados permitiram concluir que a morfogênese das ramificações dos ductos prostáticos que compõem as células epiteliais estava completa na pós-puberdade 1 , assim como o desenvolvimento do estroma muscular, fato observado em camundongos no décimo dia da vida neonatal (THOMSON, 2001). A influência dos andrógenos e as interações mesenquima-epiteliais na condução do crescimento e desenvolvimento da próstata, explicam estes resultados, pois sob concentrações relativamente baixas de andrógenos, como as esperadas até a pós-puberdade 1 (ZHAO et al., 1993; HORSFALL et al., 1994) é observada a proliferação das células mesenquimais; a sinalização parácrina do mesenquima para o epitélio promovendo o crescimento e ramificação dos ductos e a proliferação do epitélio (THOMSON, 2001) e a ação células epiteliais sob o mesenquima promovendo a diferenciação deste em estroma composto de musculo liso e fibroblastos (HAYWARD et al., 1996).

Na pós-puberdade 2 ambos, o estroma muscular e a altura do epitélio, diminuíram, sendo esta diminuição significativa para o estroma e não significativa para o epitélio. As altas concentrações de andrógenos, como as esperadas por ocorrer a partir da pós-puberdade 2 quando os testículos começam a sintetizar grandes quantidade de testosterona (ZHAO et al., 1993; HORSFALL et al., 1994), foram as responsáveis por estes achados, pois atuam mantendo a integridade funcional e secretória da próstata em níveis normais durante a vida adulta. Em consequência, a divisão das células prostáticas passa a ocorrer numa taxa muito baixa e balanceada com a morte celular; o estroma diminuiu em decorrência da expansão do compartimento de células epiteliais
(HORSFALL et al., 1994), o qual aumenta a regulação das proteínas secretórias (THOMSON, 2001) e sofre discreta diminuição devido à morte das células epiteliais por apoptose (THOMSON, 2001; CORDEIRO et al., 2004).

A correlação significativa entre o estroma muscular e altura do epitélio com a largura da próstata indicaram que as alterações nestas estruturas refletiram-se principalmente na largura da glândula e não em seu comprimento, volume ou espessura. A diminuição significativa do estroma muscular da próstata de cobaios apenas na pós-puberdade 2 contrastou com os resultados de Cordeiro et al. (2004) que observaram este fato já a partir da puberdade (entre 2 e 10 semanas após o nascimento) até a fase adulta (120 a 360 dias). Acreditamos que esta divergência ocorreu devido a diferenças na classificação etária empregada por estes autores. Quanto à discreta diminuição na altura do epitélio prostático, nossos resultados divergiram de Cordeiro et al. (2004), que observaram este fato apenas na fase adulta.

A partir dos resultados, é possível concluir que as unidades túbulo-alveolares da próstata de cobaios assemelham-se as de Chinchilla laniger; a presença de pregas altas ramificadas na mucosa às da paca; cutia e capivara, enquanto que o epitélio secretor do tipo cúbico simples assemelha-se ao de humanos e difere de outros roedores. As principais alterações detectadas com o desenvolvimento foram o aumento significativo do estroma muscular e da altura do epitélio secretor a partir da pré-puberdade tardia até a pós-puberdade $1 \mathrm{e}$ depois diminuição na pós-puberdade 2, principalmente do estroma muscular. Estes resultados fundamentam estudos futuros sobre o desenvolvimento pós-natal e de envelhecimento prostático e fundamentam o uso de cobaios como modelo experimental para pesquisas a respeito do complexo prostático.

\section{Agradecimentos}

Ao CNPq e UNIVASF pelas bolsas de iniciação científica e ao Prof. Raimundo Palheta Júnior (UNIVASF) por disponibilizar o laboratório para as análises volumétricas. 


\section{Referências}

AVERBECK, M. A.; BLAYA, R.; SEBEN, R. R.; LIMA, N. G.; DENARDIN, D.; FORNARI, A.; RHODEN, E. L. Diagnóstico e tratamento da hiperplasia benigna da próstata. Revista da AMRIGS, Porto Alegre, v. 54, n. 4, p. 471-477, 2010.

BORGES, E. D. Morfologia dos órgãos genitais de paca (Agouti paca Linnaeus 1766). 2004. 165 f. Tese (Doutorado em Medicina Veterinária) - Universidade de São Paulo, São Paulo. 2004.

CARVALHO, C. A. F. Histoquímica e ultra-estrutura do lobo ventral da próstata de ratos (Rattus norvegicus) frente ao uso prolongado de nicotina. 2005. $84 \mathrm{f}$. Tese (Doutorado em Biologia Celular e Estrutural) - Universidade Estadual de Campinas, Campinas. 2005.

CEPEDA C. R.; ADARO A. L.; PEÑAILILLO G. P. Variaciones morfométricas de la próstata de Chinchilla laniger (Molina, 1982) y de la concentración de testosterona plasmática durante un ciclo reproductivo anual. International Journal of Morphology, Temuco, v. 24, n. 1, p. 89-97, 2006.

COOPER, G.; SCHILler, A. L. Anatomy of the Guinea pig. Cambridge: Harvard University Press, 1975. 417 p.

CORDEIRO, R. S.; SCARANO, W. R.; GÓES, R. M.; TABOGA, $\mathrm{S}$. R. Tissue alterations in the Guinea pig lateral prostate following antiandrogen flutamide therapy. Biocell, Mendoza, v. 28, n. 1, p. 21-30, 2004

FERNANDEZ, D. S. Morfologia do trato reprodutor masculino de capivara: estudo das glândulas anexas à uretra. 2003. $100 \mathrm{f}$. Dissertação (Mestrado em Anatomia dos Animais Domésticos) Universidade de São Paulo, São Paulo. 2003.

FERNANDEZ, D. S.; FERRAZ, R. H. S.; MELO, A. P. F.; RODRIGUES, R. F.; SOUZA, W. M. Análise histológica das glândulas uretrais da capivara (Hydrochoerus hydrochaeris). Pesquisa Veterinária Brasileira, Rio de Janeiro, v. 30, p. 373-377, 2010.

GRADELA, A.; MARTINS, L. F. T.; NUNES, A. K. R.; SANTOS, J. M.; LINS, T. L. B.; MENEZES, V. G; FRANZO; V. S. Morphologic and morphometric aspects of the vesicular gland during development in guinea pigs (Cavia porcellus). In: ASSOCIATION FOR APPLIED ANIMAL ANDROLOGY CONFERENCE, 8, 2012, Vancouver. Proceedings...Vancouver: AAAA, 2012. p. 199.

HAYWARD, S. W.; BASKIN, L. S.; HAUGHNEY, P. C.; FOSTER, B. A.; CUNHA, A. R.; DAHIYA, R.; PRINS, G. S.; CUNHA, G. R. Stromal development in the ventral prostate, anterior prostate and seminal vesicle of the rat. Acta Anatomica, Basel, v. 155, p. 94-103, 1996.

HAYWARD, S. W.; CUNHA, G. R. The prostate: development and physiology. Radiologic Clinics of North America, Philadelphia, v. 38 , n. 1, p. 1-14, 2000.

HORSFALL, D. J.; MAYNE, K.; RICCIARDELLI, C.; RAO, M.; SKINNER, J. M.; HENDERSON, D. W.; MARSHALL, V. R.; TILLEY, W. D. Age-related changes in guinea pig prostatic stroma. Laboratory Investigation, Augusta, v. 70, n. 5, p. 753$763,1994$.

JANULIS, L.; LEE, C. Prostate gland. In: KNOBIL, E.; NEILL, J. D. (Ed.). Encyclopedia of reproduction. Vol. 4. San Diego: Academic Press, 1999. p. 77-85.
JEMAL, A.; SIEGEL, R.; XU, J.; WARD, E. Cancer statistics. CA A Cancer Journal of Clinicians, Maple Shade, v. 60, n. 5, p. 277300,2010

JUNQUEIRA, L. C.; CARNEIRO, J. Aparelho reprodutor masculino. In: JUNQUEIRA, L. C.; CARNEIRO, J. (Ed.). Histologia básica. Cap. 21. 11 ed. Rio de Janeiro: Guanabara Koogan, 2005. p. 323-334.

MANDARIM-DE-LACERDA, C. A. Manual de quantificação morfológica: morfometria, alometria, estereologia. 2. ed. Rio de Janeiro: UFRJ, Brasil, 1994. 102 p.

MARCELLI, M.; CUNNINGHAM, G. Hormonal signaling in prostatic hyperplasia and neoplasia. The Journal of Clinical Endocrinology \& Metabolism, Stanford, v. 84, n. 10, p. 34633468, 1999.

MARKER, P. C.; DONJACOUR, A. A.; DAHIYA, R.; CUNHA, G. R. Hormonal cellular and molecular control of prostatic development. Developmental Biology, Kansas City, v. 253, p. $165-$ 74, 2003.

MARTINS, D. S.; FERREIRA, J. R.; AMBRÓSIO, C. E.; AZARIAS, R. E.; OLIVEIRA, V. L.; MACHADO, M. R. F.; MIGLINO, M. A. Análise estrutural das glândulas genitais acessórias da preguiça de coleira (Bradypus torquatus, Illiger, 1811). Biotemas, Florianópolis, v. 20, n. 2, p. 89-97, 2007.

MENEZES, D. J. A. Morfologia dos órgãos genitais masculinos da cutia (Dasyprocta aguti. Linnaeus, 1766). 2001. $169 \mathrm{f}$. Dissertação (Mestrado em Anatomia) - Universidade de São Paulo, São Paulo. 2001.

MOLlineAU, W. M.; ADOGWA, A. O.; GARCIA, G. W. The gross and micro anatomy of the accessory sex glands of the male agouti (Dasyprocta leporina). Anatomia, Histologia, Embryologia, Malden, v. 38, p. 204-207, 2009.

MOURA, V. M. B. D.; SANTIS, G. W.; AMORIM, R. L.; BALIEIRO, J. C.; MUKERJEE, B.; RAJAN, T. Morphometric study of rat prostate in normal and under stressed condition. Journal of Anatomical Society of India, Bangalore, v. 53, n. 2, p. 29-34, 2004.

MUKERJEE, B.; RAJAN, T. Morphometric study of rat prostate in normal and under stressed condition. Journal of Anatomical Society of India, Bangalore, v. 53, n. 2, p. 29-34, 2004.

NEUHAUS, J.; DORSCHNER, W.; MONDRY, J.; STOLZENBURG, J-U. Comparative anatomy of the male guineapig and human lower urinary tract: histomorphology and threedimensional reconstruction. Anatomia, Histologia, Embryologia, Malden, v. 30, p. 185-192, 2001.

ORTI, R. M.; GARCIA, P. M.; SORIANO, J. G. Atlas de anatomía de animales exóticos. Barcelona: Masson, 2004. 192 p.

SHAPPELL, S. B.; THOMAS, G. V.; ROBERTS, R. L.; HERBERT, R.; ITTMANN, M. M.; RUBIN, M. A. Prostate pathology of genetically engineered mice: definitions and classification. The consensus report from the Bar Harbor meeting of the Mouse Models of Human Cancer Consortium Prostate Pathology Commitee. Cancer Research, Philadelphia, v. 61, p. 2270-305, 2004.

SROUGI, M.; RIBEIRO, L. A.; PIOVESAN, A. C.; COLOMBO, J. R.; NESRALLAH, A. Doenças da próstata. Revista de Medicina, São Paulo, v. 87, n. 3, p. 166-177, 2008.

SUZUKI, O.; KOURA, M.; NOGUCHI, Y.; TAKANO, K.; YAMAMOTO, Y.; MATSUDA, J. Optimization of superovulation 
induction by human menopausal gonadotrophin in guinea pigs based on follicular waves and FSH-receptor homologies. Molecular Reproduction and Development, Malden, v. 64, p. 219-225, 2003.

TABOGA, S. R.; VILAMAIOR, P. S. L.; GÓES, R. M. Modulação androgênica e estrogênica na próstata: uma abordagem em modelos experimentais de roedores com enfoque na biologia estrutural. Arquivo Brasileiro de Endocrinologia \& Metabologia, São Paulo, v. 53, n. 8, p. 946-955, 2009.

THOMSON, A. A. Role of androgens and fibroblast growth factors in prostatic development. Reproduction, Bristol, v. 121, p. 187195,2001
VÁSQUEZ, B.; DEL SOL, M. Estudio morfológico de la próstata y glándulas vesiculares de Cobayo (Cavia porcellus). International Journal of Morphology, Temuco, v. 28, n. 4, p. 1301-1307, 2010.

ZHANG, Y. H.; NOJIMA, S.; NAKAYAMA, H.; JIN, Y. L.; ENZA, H. Characteristics of normal stromal components and their correlation with cancer occurrence in human prostate. Oncology Reports, Athens, v. 10, p. 207-211, 2003.

ZHAO, C. Y.; TAM, C. C.; WONG, Y. C. Morphogenesis and ductal development of the prostatic complex of the guinea pig. Journal of Morphology, Malden, v. 217, p. 219-227, 1993. 